\title{
CRÍTICA DE LOS GÉNEROS LITERARIOS EN CÉFALO Y POCRIS DE CALDERÓN
}

\author{
Jesús G. Maestro \\ Facultad de Filología y Traducción \\ Universidad de Vigo \\ Campus Universitario de Vigo \\ 36310 Vigo. España \\ jesus.g.maestro@mundo-r.com
}

[Anuario calderoniano (ISSN: 1888-8046), 3, 2010, pp. 219-237]

\section{INTRODUCCIÓN}

Género es el conjunto de características comunes que pueden identificarse gnoseológicamente, es decir, según criterios formales y materiales, entre las partes que constituyen una totalidad. En consecuencia, los géneros literarios serán los diferentes conjuntos de características comunes que podrán identificarse según criterios gnoseológicos, esto es, material y formalmente, entre las partes o especies que constituyen la totalidad de las obras literarias reconocidas como tales.

Voy a exponer, de acuerdo con esta definición, y con los presupuestos del Materialismo Filosófico como Teoría de la Literatura, una crítica gnoseológica de los géneros literarios en relación con Céfalo y Pocris de Calderón ${ }^{1}$.

${ }^{1}$ El Materialismo Filosófico es una Teoría de la Literatura de naturaleza racionalista, científica, crítica y dialéctica, cuyo fin es la interpretación de las Ideas objetiva- 
En primer lugar, von a considerar los géneros literarios desde la teoría literaria, según criterios semiológicos dados en los ejes sintáctico, semántico y pragmático del espacio gnoseológico. En segundo lugar, me referiré a los géneros literarios desde la crítica literaria, es decir, desde un enfoque filosófico y dialéctico de los materiales literarios, clasificados de acuerdo con la perspectiva lógico-formal y lógico-material que ofrece la teoría holótica. Finalmente, en tercer y último lugar, tomaré como referencia y como ejemplo la comedia burlesca de Calderón titulada Céfalo y Pocris, con objeto de ofrecer una demostración crítica de la teoría de los géneros literarios propuesta por el Materialismo Filosófico.

\section{Los gÉNeros literarios SEgÚN la TeOría de la Literatura}

La Teoría de la Literatura es el conocimiento científico o conceptual de los materiales literarios ${ }^{2}$. Como Teoría de la Literatura, el Materialismo Filosófico se ocupa de los materiales literarios en términos categoriales o conceptuales. En este sentido, una poética gnoseológica de los géneros literarios sitúa al intérprete, desde una perspectiva semiológica, en el espacio de la gnoseología, lo que permitirá clasificar los materiales literarios de acuerdo con los tres ejes constituyentes de tal espacio (sintáctico, semántico y pragmático), según se indica en el esquema adjunto.

Se distinguen así, en primer lugar, en el eje sintáctico del espacio gnoseológico, tres términos de referencia que habrá que relacionar críticamente mediante operaciones interpretativas: Género, Especie y Obra literaria.

De modo semejante, en segundo lugar, en el eje semántico habrán de identificarse tres dimensiones dadas en la naturaleza lógico-formal

das formalmente en los materiales literarios. La Teoría de la Literatura es el conocimiento científico de los materiales literarios. Y su fin es demostrar que la Literatura es inteligible. Sobre el Materialismo Filosófico como Teoría de la Literatura, ver los seis vols. que constituyen su exposición y desarrollo en mi obra Crítica de la Razón Literaria (Maestro, 2006-2009).

${ }^{2}$ Los materiales literarios son esencialmente cuatro: autor, obra, lector e intérprete o transductor (Maestro, 2007a). 
(partes formales) 3 y lógico-material (partes materiales) ${ }^{4}$ de las partes que constituyen la totalidad de los géneros literarios como categorías literarias, que aquí procedo a interpretar desde una teoría holótica en virtud de la cual el Género se objetiva esencialmente mediante determinaciones intensionales, la Especie se objetiva accidentalmente mediante integraciones extensionales, y la Individualidad, en este caso la Obra literaria, se singulariza y concreta mediante constituyentes distintivos. En consecuencia, habrá que distinguir, en relación al todo que constituye la literatura, tres tipos de partes:

1) Intensionales o determinantes: son las partes que consideraremos esenciales o intensionales, esto es, las que constituyen la Esencia o Canon de la totalidad a la que pertenecen, y las que, en consecuencia, permiten adscribir tal o cual especie u obra literaria concreta a un género determinado y determinante. Por ejemplo, la parte determinante o intensional del teatro como género literario es la relación de conjugación o interdependencia entre texto literario y texto espectacular.

2) Extensionales o integrantes: son aquellas partes que consideraremos estructurantes o aditivas, es decir, las que objetivan los rasgos específicos (que no genéricos) de esa totalidad, y que, por lo tanto, permiten adscribir tal o cual obra literaria a una especie determinada. Por ejemplo, la comedia burlesca tendrá, entre sus partes determinantes, personajes mitológicos, legendarios, figuras del Romancero, así como todo tipo de chanzas,

3 Partes formales son partes que constituyen la forma del todo. Son un «trozo» de la forma del todo. Su morfología presupone, genética o estructuralmente, la forma de la totalidad en que se integran. Como parte de la forma del todo, son partes integrantes y determinantes de la estructura formal del todo, es decir, partes esenciales y accidentales de la morfología del todo (un cristal que resulta de una botella rota o hecha pedazos). En un soneto, son partes formales los dos cuartetos y los dos tercetos. También lo son (en el caso del soneto aurisecular) los versos endecasílabos, que han de ser catorce, si el soneto no lleva estrambote.

${ }^{4}$ Partes materiales son aquellas que no determinan la forma del todo, esto es, partes que no revelan ni contienen en su morfología la forma de la totalidad de la que forman parte. Las partes materiales no son, pues, una parte de la forma del todo, sino su sustancia material (las moléculas del cristal con el que está hecho una botella). Pueden ser integrantes, determinantes y constituyentes de la materia de la que está hecho el todo, pero no de la forma del todo. Las partes materiales son esenciales, pero no genéricas. En un soneto, son partes materiales los fonemas, las grafias, los lexemas y monemas, etc. 
juegos verbales, chistes, pullas, disparates, inversiones del decoro, etc. Se tratará, en suma, de partes extensionales que no estarán presentes, con la misma recurrencia e intención, en la comedia seria, en la tragedia o en el teatro hagiográfico, por ejemplo.

3) Distintivas o constituyentes: son aquellas partes que se identifican como diferenciales o singulares de una obra literaria particular dentro de la totalidad genérica (género) o específica (especie) a la que tal obra se adscribe o pertenece, es decir, son partes que constituyen o diferencian los rasgos propios en virtud de los cuales es posible individualizar una obra literaria concreta por referencia a su especie. Son características que definen lo distintivo o constitutivo de una comedia particular, por ejemplo Céfalo y Pocris, en el caso de la comedia burlesca, frente al género (la comedia en general o la comedia nueva lopesca en particular) y frente a la especie (comedia hagiográfica o de santos, comedia turquesca, comedia de capa y espada, comedia de historia, comedia divina, comedia humana, comedia imaginada, etc.).

Por último, en tercer lugar, en el eje pragmático del espacio gnoseológico el intérprete habrá de establecer un sistema de relaciones cogenéricas — dadas en todas las Especies del mismo Género $\left(\mathrm{E}_{\mathrm{g}}\right)$ de relaciones subgenéricas - distintivas o específicas de una Especie $\left(\mathrm{E}_{1}\right)$ - y de relaciones transgenéricas — presentes en dos o más Géneros $\left(\mathrm{G}_{\mathrm{x}}, \mathrm{G}_{\mathrm{y}}, \mathrm{G}_{\mathrm{z}} \ldots\right)$ -

$\int$

Poética gnoseológica de los géneros literarios

(enfoque semiológico, en términos categoriales o conceptuales):

el Materialismo Filosófico como Teoría de la Literatura

Eje sintáctico

\begin{tabular}{|c|c|c|}
\hline Género & Especie & $\begin{array}{c}\text { Individualidad = Obra } \\
\text { literaria }\end{array}$ \\
\hline$(\mathrm{G})$ & $(\mathrm{E})$ & $(\mathrm{I})$ \\
\hline$($ El teatro $)$ & (La comedia) & (Céfalo Y Pocris) \\
\hline
\end{tabular}


Eje semántico

\begin{tabular}{|c|c|c|}
\hline \multicolumn{3}{|c|}{ Partes de una Totalidad } \\
\hline \multicolumn{3}{|c|}{ consideradas } \\
\hline Esencialmente & Accidentalmente & Singularmente \\
\hline \multicolumn{3}{|c|}{ como: } \\
\hline Partes determinantes & $\begin{array}{c}\text { Partes } \\
\text { integrantes } \\
\text { o intensionales }\end{array}$ & $\begin{array}{c}\text { Partes } \\
\text { constituyentes } \\
\text { o distintivas }\end{array}$ \\
\hline (La comedia) & $\begin{array}{c}\text { (La comedia burlesca o de } \\
\text { disparates) }\end{array}$ & (Céfalo y Pocris) \\
\hline
\end{tabular}

Eje pragmático

\begin{tabular}{|c|c|c|}
\hline Cogenérico & Transgenérico & Subgenérico \\
\hline$(\mathrm{Eg})$ & $(\mathrm{Gx}, \mathrm{Gy}, \mathrm{Gz} .)$. & $(\mathrm{E} 1)$ \\
\hline $\begin{array}{c}\text { (El texto espectacular en } \\
\text { todas las especies } \\
\text { dramáticas del género } \\
\text { teatral) }\end{array}$ & $\begin{array}{c}\text { (El verso en el teatro y en } \\
\text { la lírica como géneros } \\
\text { literarios independientes })\end{array}$ & $\begin{array}{c}\text { (La ruptura del decoro en } \\
\text { la comedia burlesca como } \\
\text { especie del género teatral) }\end{array}$ \\
\hline
\end{tabular}

\section{Los géneros literarios Según la Crítica de la Literatura}

La Crítica de la Literatura es el conocimiento filosófico o crítico de las Ideas objetivadas formalmente en los materiales literarios. Como Crítica de la Literatura, el Materialismo Filosófico se ocupa de los materiales literarios en términos críticos, esto es, filosóficos y dialécticos. En este sentido, una poética gnoseológica de los géneros literarios si- 
túa al intérprete ante la doble perspectiva, lógico-formal y lógico-material, propia de toda gnoseología, tal como se indica en el esquema adjunto.

Lo que ofrezco aquí, en su doble perspectiva lógico-formal y lógico-material, es lo que puede considerarse como el sistema de los nueve Predicados Gnoseológicos de los Géneros Literarios: esencia o canon, atributo o metro, potencia, paradigma, facultad, propiedad, prototipo, característica y accidente 5 .

Una exposición gnoseológica de tales predicados en cada una de estas perspectivas tendrá que distinguir los rasgos genéricos, específicos e individuales, es decir, respectivamente, los del género, la especie y la obra literaria:

$\int$

Poética gnoseológica de los géneros literarios (enfoque filosófico, en términos críticos o dialécticos): el Materialismo Filosófico como Crítica de la Literatura

Perspectiva Lógico-Formal

\begin{tabular}{|c|c|c|c|}
\hline Partes / Totalidades & Género & Especie & Obra literaria \\
\hline $\begin{array}{c}\text { Determinante } \\
\text { o intensional }\end{array}$ & ESENCIA O CANON & PARADIGMA & Prototipo \\
\hline $\begin{array}{c}\text { Integrante } \\
\text { o extensional }\end{array}$ & $\begin{array}{c}\text { ATRIBUTO O } \\
\text { METRO }\end{array}$ & FACULTAD & CARACTERÍsTICA \\
\hline $\begin{array}{c}\text { Constituyente } \\
\text { o distintiva }\end{array}$ & POTENCIA & PROPIEDAD & ACCIDENTE \\
\hline
\end{tabular}

${ }^{5}$ Para una interpretación más amplia de estos predicados, ver mi monografía al respecto (Maestro, 2009). 
Perspectiva Lógico-Material

\begin{tabular}{|c|c|c|c|}
\hline Partes / Totalidades & $\begin{array}{l}\text { GÉnERo } \\
\text { Teatro }\end{array}$ & $\begin{array}{c}\text { EsPECIE } \\
\text { Comedia burlesca }\end{array}$ & $\begin{array}{c}\text { Obra literaria } \\
\text { Céfalo y Pocris }\end{array}$ \\
\hline $\begin{array}{l}\text { DETERMINANTE } \\
\text { O INTENSIONAL }\end{array}$ & $\begin{array}{c}\text { ESENCIA O CANON } \\
\text { Texto literario } \\
y \\
\text { Texto espectacular }\end{array}$ & $\begin{array}{c}\text { PARADIGMA } \\
\text { Comedia burlesca } \\
\text { o de disparates, como } \\
\text { paradigma intensio- } \\
\text { nalizado } \\
\text { de forma específica }\end{array}$ & $\begin{array}{c}\text { Prototipo } \\
\text { Prototipos literarios } \\
\text { objetivados } \\
\text { y generados } \\
\text { por las figuras } \\
\text { míticas de } \\
\text { Céfalo y Pocris }\end{array}$ \\
\hline $\begin{array}{c}\text { INTEGRANTE } \\
\text { O EXTENSIONAL }\end{array}$ & $\begin{array}{c}\text { Atributo o } \\
\text { Metro } \\
\text { Formas cómicas inte- } \\
\text { grables en el formato } \\
\text { de la comedia burles- } \\
\text { ca o de disparates }\end{array}$ & $\begin{array}{c}\text { FACUlTAD } \\
\text { Desmitificación } \\
\text { burlesca } \\
\text { de figuras legendarias } \\
\text { de la mitología } \\
\text { grecolatina }\end{array}$ & $\begin{array}{c}\text { CARACTERÍsTICA } \\
\text { El ridículo }\end{array}$ \\
\hline $\begin{array}{c}\text { CONSTITUYENTE } \\
\text { O DISTINTIVA }\end{array}$ & $\begin{array}{l}\text { Potencia } \\
\text { La parodia }\end{array}$ & $\begin{array}{l}\text { PROPIEDAD } \\
\text { El carnaval }\end{array}$ & $\begin{array}{c}\text { ACCIDENTE } \\
\text { El chiste }\end{array}$ \\
\hline
\end{tabular}

1. Los rasgos genéricos de una obra de arte pueden predicarse genéricamente [esencia o canon], específicamente [atributo o metro] o singularmente [potencia], es decir, según sus notas esenciales, intensivas o determinantes (del género), que en efecto se predicarán, bien como tales (del género desde el género), bien como partes extensionales o integrantes (de la especie desde el género), bien como partes constituyentes o distintivas (del individuo desde el género).

2. Los rasgos específicos de una obra de arte pueden predicarse genéricamente [paradigma], específicamente [facultad] o singularmente [propiedad], es decir, según sus notas extensionales o integrantes (de la especie), que en efecto se predicarán, bien como partes esenciales, determinantes o intensionales (del género desde la especie), bien como 
partes extensionales o integrantes (de la especie desde la especie), bien como partes constituyentes o distintivas (del individuo desde la especie).

3. Los rasgos individuales de una obra de arte pueden predicarse genéricamente [prototipo], específicamente [característica] o singularmente [accidente], es decir, según sus notas constituyentes o distintivas (del individuo), que en efecto se predicarán, bien como partes esenciales, intensivas o determinantes (del género desde el individuo), bien como partes extensionales o integrantes (de la especie desde el individuo), bien como partes constituyentes o distintivas (del individuo desde el individuo).

\section{Los géneros literarios en Céfalo y Pocris}

Todavía en 1999 diferentes autores coincidían en señalar que la comedia burlesca era un género teatral al que la crítica había prestado poca atención ${ }^{6}$. Como ha señalado García Lorenzo ${ }^{7}$, "cuatro son los términos con que califican a este tipo de obras sus autores o editores: burlesca, de disparates, de chanza o de chistes». En efecto, la comedia burlesca es una especie cómica del género teatral que, concebida específicamente en el Siglo de Oro, se sitúa en los límites más extremos de la formalización de una materia que, otras formas o especies de comedia aurisecular, no teatralizan de modo tan burlesco, disparatado o paródico. Estamos, pues, ante un género teatral determinado específicamente por las formas más extremas de la materia cómica conceptualizables en la literatura del Siglo de Oro. Adviértase además que la extensión de la comedia burlesca (unos mil ochocientos versos) tiene a ser algo superior a la mitad, aproximadamente, de lo que sería una comedia nueva convencional (unos tres mil versos) ${ }^{8}$.

Desde el punto de vista de la sociología de la comedia burlesca, como ha señalado Arellano ${ }^{9}$, la mayor parte de las obras de esta especie, se-

${ }^{6}$ Ver Arellano, García Valdés, Mata Induráin y Carmen Pinillos (1999, p. 9). Son de referencia sobre el género de la comedia burlesca los trabajos precedentes de Serralta (1980) y García Lorenzo (1994), entre otros que se irán señalando.

7 1987, p. 124.

8 Céfalo y Pocris es en este punto una excepción, pues sobrepasa los 2000 versos.

${ }^{9}$ Arellano, 1995, pp. 641 y ss. 
gún los datos disponibles, se representaron durante el reinado de Felipe IV (1621-1665), y a lo que parece preferentemente superada la mitad de la centuria, lo que nos sitúa en uno de los momentos más tardíos del Barroco. Se trata además de piezas destinadas a representarse en tiempos de Carnestolendas y en espacios palatinos. Barroco tardío, carnaval y palacio real, serán elementos condicionantes de esta especie cómica del género dramático aurisecular.

Por su parte, los temas de la comedia burlesca se refieren con frecuencia a los dominios de la mitología, la literatura y el teatro, concretamente a la mitología grecolatina, las literaturas románicas y el teatro aurisecular contemporáneo. El modo de referencia fundamental es la parodia, cuyo objeto son figuras, acciones y diálogos mitológicos, literarios y teatrales de referencia popular y culta (Céfalo y Pocris, Los siete infantes de Lara, Las mocedades del Cid de Cáncer, Durandarte y Belerma, El caballero de Olmedo de Monteser...).

1. Esencia o canon: el texto literario y el texto espectacular. El teatro es literatura para ser representada. La esencia o canon del teatro como género literario tiene su núcleo en la relación conjugada, o de interdependencia mutua, entre el texto literario (los diálogos de los personajes y aquellas acotaciones que posean valor estético) y el texto espectacular (el conjunto de informaciones contenidas en la obra teatral, tanto en los diálogos como en las acotaciones, y destinadas a su puesta en escena). En suma, la esencia o canon de una obra de arte define sus rasgos genéricos según las partes determinantes o intensionales en ella objetivadas, es decir, en el caso de la comedia burlesca, el texto literario y el texto espectacular.

2. Metros o atributos: las formas cómicas integrables en el formato de la comedia burlesca. Los metros o atributos de una obra de arte definen sus rasgos genéricos según las partes integrantes o extensionales en ella objetivadas, de modo que, en el caso de la comedia burlesca, pueden identificarse los siguientes metros o atributos, como segmentos integrantes o elementos extensionales de este género dramático, con frecuencia señaladas por diferentes estudiosos ${ }^{10}$, la literatura jocosa del

${ }^{10}$ Ver Chevalier, 1992; García Lorenzo, 1994; García Valdés, 1991, pp. 33-40; Serralta, 1980. 
Romancero nuevo, las composiciones satíricas y burlescas, la parodia poética de corte quevediano y gongorino, diálogos fuertemente jocosos y entremesiles, expresiones punzantes, vejámenes, chistes, pullas, elementos propios de las fiestas de locos medievales, «incoherencia cómica (muertos que reviven, inversiones del decoro, alegrías por las deshonras, venganzas grotescas... $)^{11}$ ", preservación de una intriga, en sí misma apenas relevante, como pretexto de cohesión de sucesivas situaciones cómicas y paródicas...

En el caso de la comedia burlesca, los metros o atributos exigen una cita con las formas de la materia cómica: caricatura, carnaval, chiste, escarnio, farsa, grotesco, humor, ironía, parodia, ridículo, risa y sátira. Y hemos de hacernos la siguiente pregunta: ¿cuáles son las formas que, de modo dominante, hacen sensible e inteligible la materia cómica presente en las comedias burlescas? Esencialmente - que no exclusivamente - hay cuatro formas muy dominantes: el carnaval, la parodia, el chiste y lo ridículo. No se pretende el escarnio, ni abunda lo grotesco. Tampoco es recurrente la caricatura. El humor y la ironía resultan eclipsados por formas cómicas que buscan la risa y la carcajada más que la sonrisa, la reflexión y la crítica. Todo este tratamiento de las formas de la materia cómica dice mucho a propósito de esta especie del género dramático aurisecular, propia de un Barroco tardío, de referentes míticos, legendarios y literarios, que ha dado en llamarse comedia burlesca. Nos hallamos, sin duda, ante una forma de hacer teatro de pretensiones lúdicas, acríticas e, innegablemente, escapistas, pero profundamente culta, por su implicación en temas, motivos y referentes que están en la base de la cultura y la literatura occidentales, a los que parodia desde un extrañamiento que acaso podría verse como precursor de algunos disparates goyescos, de esperpentos y expresionismos valleinclanianos, de títeres lorquianos y, por supuesto, incluso desde un contexto más amplio, de un teatro vanguardista propio del comienzos del siglo xx europeo.

Parodia, carnaval, chiste y ridículo no son cuatro formas cualesquiera de materia cómica. Son formas muy reveladoras y muy representativas de un determinado modo de expresar la materia cómica. Son, frente la ironía, el humor, el escarnio, la sátira, la caricatura o lo grotesco, las formas más espontáneas, mejor aceptadas y menos ofen-

11 AA.VV., 1999, p. 12. 
sivas que pueden darse en la experiencia cómica una sociedad política madura. Por su parte, la ironía, el humor, el escarnio, la caricatura incluso, y lo grotesco sin duda, son formas cómicas mucho más amargas, crudas y reaccionarias, así como también más artificiosas y sofisticadas, al buscar consecuencias menos lúdicas y de mayor calado crítico y reflexivo. A continuación, voy a referirme a cada una de ellas - parodia, carnaval, ridículo y chiste-, desde el punto de vista de la relación formal y material que adquieren respectivamente como potencias, propiedades, características y accidentes observables en una crítica de los géneros literarios en Céfalo y Pocris.

3. Potencias: la parodia. Cuatro son los elementos fundamentales que determinan la naturaleza de la parodia: 1) el artífice o autor de la parodia, 3) el sujeto o personaje que ejecuta la parodia, 3) el objeto o referente burlescamente imitado, y 4) el código de la parodia, que sirve de marco de referencia contextual a su interpretación, es decir, el sistema de referencias que hace posible y visible la degradación del objeto parodiado. Se observará que Calderón hace un uso de la parodia muy diferente en sus entremeses y en sus comedias burlescas, específicamente en Céfalo y Pocris.

Así, por ejemplo, en un entremés como El desafío de Juan Rana, el artífice de la parodia no es otro que Calderón, su autor; el sujeto que la ejecuta es el protagonista que da título al entremés, Juan Rana; el objeto o referente de la burla es el prototipo humano del bobo o simple, caricaturizado y ridiculizado en la figura del protagonista; y el código en virtud del cual interpretamos esta parodia es el código del honor aurisecular. Este esquema, con variantes exclusivamente accidentales, se reproduce de forma regular en casi todos los entremeses de Calderón. Sucede que la crítica calderoniana, al ocuparse de su obra cómica breve, se ha limitado con frecuencia a exaltar de forma más entusiasta que rigurosa lo paródico en el teatro de Calderón, así como a describir retóricamente algunos de los infinitos recursos formales usados por el dramaturgo para expresar comicidad. Resultado de esta tendencia ha sido confundir de forma reiterada el código de la parodia con el objeto de la imitación burlesca, es decir, el código del honor con el prototipo del bobo o simple, dicho con otras palabras, lo burlescamente imitado en el entremés con aquello que hace posible su degradación. En verdad se trata de dos realidades lógicas materialmente 
diferentes, que de forma obligatoria han de ser discriminadas para comprender la verdadera naturaleza paródica de estos entremeses. A partir de esta confusión de conceptos - del objeto de la parodia con el código-, la crítica ha dictaminado que Calderón parodia en sus entremeses la idea del honor, cuando lo que real y materialmente parodia es la estulticia y la torpeza de aquellos individuos incapaces de salvaguardar, poseer y hacer valer, la idea del honor que la sociedad española aurisecular exige a sus miembros. Lejos de discutir el dogma, Calderón lo confirma también en su obra cómica breve ${ }^{12}$.

Sin embargo, algo muy diferente va a suceder en la comedia burlesca, donde el artífice de la parodia, Calderón, convierte a su propia obra no sólo en el código, sino también en el objeto de la parodia. No en vano Céfalo y Pocris es una pieza teatral desde la que su mismo autor parodia buena parte de su propia obra dramática. En este caso se produce un sincretismo entre el código y el objeto de la parodia: el teatro serio aurisecular, y específicamente el teatro calderoniano.

La parodia es sin duda la forma cómica que dispone en Céfalo y Pocris de mayor potencia e intertextualidad críticas de las cuatro, frente al carnaval, el chiste y lo ridículo, pese a que en la comedia burlesca semejante potencial crítico está disuelto lúdicamente en una mitología estoica y fabulosa o en una literatura sometida a una suerte de extrañamiento o distanciamiento contemporáneo, como sucede respecto a Las mocedades del Cid de Jerónimo de Cáncer o a El caballero de Olmedo de F. A. de Monteser.

Calderón, como se ha dicho, se parodia aquí a sí mismo, sobre todo la fiesta musical Celos aún del aire matan, y algunas escenas de Auristela $y$ Lisidante. La parodia de motivos y detalles escénicos empieza con los primeros versos, cuando aparece el príncipe Rosicler despeñado por un burro, o el motivo de la gruta, ambos presentes en piezas como La vida es sueño y muchas otras ${ }^{13}$.

4. Paradigmas: la comedia burlesca. Los paradigmas permiten inventariar y explicar las partes determinantes o intensionales del género literario de una obra concreta desde el punto de vista de la especie, in-

12 Ver Maestro, 2008.

${ }^{13}$ Ver AA. VV., 1999, p. 31. 
cidiendo en la relación de semejanza existente entre los rasgos paradigmáticos que, reproducidos en la obra literaria, definen la especie desde el punto de vista del género. El paradigma, en este sentido, será la comedia burlesca o de disparates.

La comedia de disparates es pura farsa. En términos convencionales, la farsa se concibe como una pieza cómica breve destinada a provocar la risa de sus espectadores.

Para estudiosos como Arellano ${ }^{14}$ y los miembros de GRISO, Céfalo y Pocris es "una de las mejores comedias, sino la mejor, del género", hasta el punto de considerarla como «un ejemplo arquetípico de la mejor calidad dentro del género que pretendemos recuperar ${ }^{15}$ ». Arquetípico y paradigmático serían, en este contexto, términos isovalentes.

5. Facultades: la desmitificación burlesca. El concepto de facultad, de acuerdo con la teoría de los géneros literarios desarrollada por el Materialismo Filosófico, designa las partes integrantes o extensionales de una obra literaria concreta dadas por relación a la especie a la que esta obra pertenece. En este caso, se considerarán como partes extensionales de Céfalo y Pocris aquellas que, integradas en esta comedia, la adscriben a la especie de comedia burlesca o de disparates, dada la desmitificación de referentes literarios en ella contextualizados e intertextualizados, si bien de forma diferente frente a otras especies (o comedias burlescas) del mismo género (la comedia nueva).

6. Propiedades: el carnaval. El carnaval es aquella representación en la que los valores de una sociedad, codificados oficialmente como serios, se manifiestan invertidos en un sentido cómico, paródico y grotesco, que se proyecta por igual sobre todas las clases sociales, sin discriminación, ni consideración, ni respeto de ningún tipo. El carnaval es la forma de la materia cómica que con toda nitidez representa a uno de los elementos nucleares de la comedia burlesca: la imagen del «mundo al revés», esencia misma de lo disparatado, que, por irremediable e irreversible, resulta ya inofensivo. Son de cita obligada en este punto las palabras de García Lorenzo ${ }^{16}$ :

\footnotetext{
14 Arellano, 2005.

${ }^{15}$ Ver AA.VV., 1999, pp. 31 y 36.

16 1987, p. 123.
} 
Todo estaba al revés, todo había sufrido una transformación y el aliento trágico, las pasiones amorosas, los rabiosos celos, los abusos por razones de Estado y los sacrificios inocentes, se habían convertido en bufonadas, en ridículas y grotescas figuras de carnaval, en declaraciones estúpidas, en diálogos casi surrealistas, en jocosas situaciones invitando a la carcajada, en un desenlace que ponía en escena al monarca bailando con sus súbditos y participando su real majestad en la degradación desmitificadora, al igual que en otras muchas piezas de este tipo de teatro los dramaturgos lo hacen con maridos cornudos o bobos estereotipados.

El carnaval es la parodia del mundo normativo, la inversión burlesca de los valores culturales reconocidos como serios y oficiales en una determinada sociedad política. En este punto, la comedia burlesca es la forma suprema de parodia carnavalesca alcanzada por el teatro áureo, muy por encima del entremés o de cualesquiera otras formas de teatro breve.

Frente a los padres y hermanos defensores del honor, los personajes de estas comedias se alegran y divierten con las deshonras familiares [...]. Caballeros cobardes, reyes grotescos que bailan, gritan, cantan en escena [...] son los protagonistas de estas acciones que se divierten poniendo al revés el sistema aceptado: precisamente a esta técnica del «mundo al reves» obedecen en buena medida las piezas de este género ${ }^{17}$.

Como período de fiesta, el carnaval es un momento en el que se suspenden las normas, en el que se puede hacer cosas que normalmente no se puede hacer: es un momento de inmunidad y de impunidad. La comedia burlesca expresa precisamente esa situación. Sus personajes y protagonistas están exentos de los imperativos del honor y de las exigencias del orden moral trascendente, tanto en el orden político como incluso en el teológico. He aquí el concepto de lo lúcico que, acaso sólo desde el contexto de la representación palatina, alcanza el teatro aurisecular del Barroco tardío. Es un teatro exento de crítica $^{18}$, que se entrega voluntaria y consensuadamente a la ludopatía

${ }^{17}$ Ver AA. VV., 1999 , p. 14.

18 Tal es la opinión de Serralta (1980) y Arellano (1995), a la que me adhiero, frente a la de García Lorenzo (1994), que atribuye a la comedia burlesca un valor crítico: «En realidad, más que verdadera crítica social, política o ideológica, destaca el distanciamiento burlesco respecto de los mecanismos literarios y teatrales de los gé- 
palatina y que recorre la literatura y la cultura precedentes en busca de risa, carnaval y parodia. Es un teatro que representa el agotamiento de una época pronta a concluir, y que se resiste de estos modos al aburrimiento cortesano ${ }^{19}$.

7. Prototipos: intertexto de las figuras literarias de Céfalo y Pocris. Las figuras de Céfalo y Pocris son partes esenciales o intensionales de numerosas obras literarias. La tradición intertextual en la que se insertan es amplia y provechosa ${ }^{20}$. El tema está presente en Ovidio (Metamorfosis, VII, y Arte de amar, III), y en varios autores españoles auriseculares (Jorge de Montemayor, Lomas Cantoral, Lucas Rodríguez, Agustín de Salazar...) En Italia tuvo cierta difusión en el primer teatro cortesano de finales del xv (Niccoló da Correggio, Fabula de Cefalo, ca. 1495). Es posible que en la pieza del autor ferrarés haya cierta influencia de Boiardo (Novella de Prasildo y Tisbina). También se perciben ecos del motivo en los cuentos de Maestro Anselmo, en el Orlando furioso de Ariosto. Son los cuentos que tienen que ver con Reinaldos y el vaso de oro y, claro está, con el Curioso impertinente de Cervantes.

8. Características: el ridículo. El ridículo se identifica con aquella experiencia cómica cuyos contenidos se perciben e interpretan como ajenos e inferiores a lo normativo, ortodoxo o convencionalmente respetable, y por ende susceptible de convertirse en objeto de burla. Esta Idea de Norma o de ortodoxia, dada en una determinada sociedad, es resultado de la Idea de Razón o logos, vigente en esa sociedad. Lo ridículo es con frecuencia una devaluación de lo material y formalmente aceptado como normativo o racional en una sociedad concreta. Es ridículo lo que presenta o contiene una deformación devaluada de lo normativo aceptado o de la razón establecida. Es ridículo lo

neros serios; en este sentido, la comedia burlesca comparte la misma esfera de connotaciones que las parodias de los temas mitológicos o pastoriles en la poesía (AA.VV., 1999, p. 15).

19 "Céfalo y Pocris se estrenó “en el Salón Real de Palacio", que pudo ser el salón de comedias del Alcázar o uno de los dos salones del Buen Retiro, en las fiestas de Carnaval, pero no podemos precisar la fecha de representación o la de composición" (AA.VV, 1999, p. 31). La comedia, como se sabe, vio la luz en 1691, en la impresión de Juan de Vera Tassis de la Novena Parte de Comedias de Calderón.

${ }^{20}$ Ver Navarro, 1979, p. xv, nota 5; González, 1978. 
que se percibe como fuera de lo normal y por debajo de ello, lo que, ajeno a la razón impuesta, y sustraído al logos imperante, se conceptualiza como materia disonante, susceptible de experiencia cómica, y objeto de burla. Lo ridículo no pertenece a lo respetable, desde el momento en que se sustrae a la razón normativa, al logos oficialmente codificado. Esta condición de lo ridículo, el estar por debajo de lo respetable, y convertirse en objeto de burla precisamente por eso, por estar situado debajo del umbral de lo normativo, de lo aceptado, de lo exigido, esto es, por ser una sub-normalidad, constituye, según el materialismo filosófico, su condición esencial. Lo ridículo en sí mismo no es necesariamente dañino, ni agresivo, ni violento: no hace falta combatirlo con hechos, ni siquiera con actos, sino que basta identificarlo con burlas, risas, ironías, es decir, palabras y expresiones orgánicas más o menos momentáneas. Lo ridículo suele ser con frecuencia una cualidad propia de seres vulnerables, débiles, deficientes, es decir, seres situados debajo del umbral de lo racionalmente exigido, seres, en suma, sub-normales. El ridículo es una de las figuras cómicas más utilizadas por Quevedo en sus entremeses y por Calderón en la comedia burlesca. Es también la más inocente, inofensiva e incluso acrítica, de las formas cómicas. Con frecuencia, quien lo protagoniza es una persona incapaz de llevar una vida normativa e inconsciente de tal incapacidad. El ridículo es, por desgracia, una consecuencia de la subnormalidad, es decir, de una vida que discurre por debajo de las normas habitualmente exigidas a los seres humanos. El ridículo se manifiesta sobre todo en los signos teatrales no verbales de las comedias burles$\operatorname{cas}^{21}$.

9. Accidentes: el chiste. Es la expresión verbal o iconográfica de ingenio irónico, crítico o humorístico. Pese a ser una de las formas más punzantes y sintéticas de la experiencia cómica, el chiste es también por ello mismo una de las expresiones más efimeras en la intensidad de su impacto, fácilmente soluble sin mayores consecuencias que la risa inmediata y espontánea. El chiste, a diferencia de lo ridículo, se manifiesta sobre todo en los signos teatrales de naturaleza verbal: concatenación de disparates, interpretaciones literales de expresiones he-

21 «Las comedias burlescas suelen insistir en el vestido ridículo y en la gestualidad exagerada y grotesca» (AA.VV, 1999, p. 15). 
chas, alusiones obscenas, referencias escatológicas, pullas verbales, juegos de palabras, metáforas caricaturescas, recurrencias paremiológicas, ripios deliberados, agudezas verbales, absurcedes cómicas ${ }^{22} \ldots$

No hay que olvidar que el objetivo de las formas de la materia cómica es la risa, y que ésta es ante todo el efecto orgánico del placer cómico. A su vez, lo cómico se interpretará aquí como el efecto risible provocado por la dialéctica — nunca dolorosa o amenazante para el sujeto que ríe- entre la materialización de los hechos tal como éstos han tenido lugar frente a las convenciones sociales y la materialización de los hechos tal como éstos deberían haber tenido lugar de acuerdo con las convenciones sociales. Lo cómico se basa, pues, en la dialéctica o disidencia entre los hechos consumados (facta consummata) y los hechos exigidos (facta oportebant $)^{23}$. Los hechos consumados son materialmente objetivables, visibles, constatables. Los hechos exigidos lo son de acuerdo con un código socialmente establecido e impuesto. Siempre hay un determinado tipo de logos o razón que impera en cada situación o sociedad, y que dispone, naturalmente desde un código moral, sus posibilidades de interpretación y sus requisitos de exigencia. El sujeto protagonista de los hechos consumados será objeto de risa, si sus actos no responden a lo establecido en el código de los hechos exigidos, código social que harán valer, mediante la risa y sus consecuencias, los sujetos que puedan cumplir con tales exigencias, que puedan sustraerse a ellas, o que simplemente resulten exentos de su cumplimiento. Sitúo, por tanto, la esencia de lo cómico en la dialéctica entre el ser y el deber ser - de modo que ser equivale a una materialidad consumada no

22 Sobre las posibilidades y modalidades de representación de la comedia burlesca, ver Pascual Bonis, 1998.

23 Oportere es verbo impersonal latino usado, entre otros, por Quintiliano, cuando habla de cómo conviene que sea la ley, o por Terencio, cuando se refiere a lo que conviene que alguien haga (Heautontimorúmeno, v. 536). Este verbo remite en su significado a lo que es conveniente, necesario o razonable. Su naturaleza impersonal lo hace especialmente adecuado a contextos morales y sociales. No por casualidad lo conveniente hace alusión con frecuencia a situaciones morales. Terencio escribe esta frase: Haec facta ab illo oportebant (esto es lo que él tenía que haber hecho). Me acojo aquí a la expresión facta oportebant, documentada en latín, y que sería algo así como «los hechos que convenían", lo que alguien debía haber hecho de acuerdo a una determinada situación. A su vez, los facta oportent serían los hechos que convienen, o hechos convenientes (pero esta forma, hasta donde yo sé, no está documentada en latín). 
sólo fisicamente, sino también psicológica y conceptualmente-, es decir, entre lo que alguien es realmente y lo que debería ser - pero no consigue ser dadas sus limitaciones, con frecuencia inconscientes o incontrolables - en una determinada situación, la cual lo convierte en sujeto involuntario de una experiencia cómica. Nadie — salvo un cómico profesional - se convierte consciente y voluntariamente en objeto de risas y burlas. En el caso del cómico profesional, no es su persona, sino su personaje, es decir, el prototipo que representa o interpreta, objeto de risa y sujeto de experiencia cómica. 


\section{Bibliografía}

AA.VV., Comedias burlescas del Siglo de Oro. El Hamete de Toledo. El caballero de Olmedo. Darlo todo y no dar nada. Céfalo y Pocris, ed. I. Arellano, C. C. García Valdés, C. Mata y M. C. Pinillos, Madrid, Espasa Calpe, 1999.

Arellano, I., "La comedia burlesca y los géneros breves», Historia del teatro español del siglo XVII, Madrid, Cátedra, 1995, pp. 641-684.

Casado, M. J., "El Arte nuevo de hacer comedias "a través del espejo": la comedia burlesca del Siglo de Oro», Hispania Felix, 1, 2010, pp. 151-168.

Chevalier, M., Quevedo y su tiempo: la agudeza verbal, Barcelona, Crítica, 1992.

García Lorenzo, L., "De la tragedia a la parodia: El caballero de Olmedo», en «El castigo sin venganza» y el teatro de Lope de Vega, Madrid, Cátedra, 1987, pp. 123-140.

- «Procedimientos cómicos en la comedia burlesca», en Del horror a la risa. Los géneros dramáticos clásicos. Homenaje a Christiane Faliu-Lacourt, ed. I. Arellano, V. García Ruiz y M. Vitse, Kassel, Reichenberger, 1994, pp. 89113.

García Valdés, C. C., De la tragicomedia a la comedia burlesca: El caballero de Olmedo, Pamplona, Eunsa, 1991.

GonzÁlez, E., "Carnival on the Stage: Céfalo y Pocris, comedia burlesca», Bulletin of the Comediantes, 30, 1978, pp. 3-12.

Maestro, J. G., «La parodia en el teatro cómico breve de Calderón», en Calderón y el pensamiento ideológico y cultural de su época, XIV Coloquio Anglogermano sobre Calderón, 24-28 julio 2005, Archivum Calderonianum, 11, ed. M. Tietz y G. Arnscheidt, Stuttgart, Franz Steiner Verlag, 2008, pp. 337366.

Navarro, A., "Calderón», en Céfalo y Pocris, ed. A. Navarro, Salamanca, Almar, 1979, pp. xi-liv.

Pascual Bonis, M., "Puesta en escena y recepción de la comedia burlesca: El caballero de Olmedo de F. A. de Monteser», en Actas del IV Congreso Internacional Siglo de Oro (AISO), ed. M. C. García de Enterría y A. Cordón Mesa, Alcalá de Henares, Universidad de Alcalá de Henares, 1998, vol. II, pp. 1145-1157.

Serralta, F., «La comedia burlesca: datos y orientaciones», Risa y sociedad en el teatro español del Siglo de Oro, Paris, CNRS, 1980, pp. 99-129. 